\title{
Utilization of Virtual Globes for Open Source Industrial Symbiosis
}

\author{
William Doyle and Joshua M. Pearce*
}

Department of Mechanical and Materials Engineering, Queen's University, 60 Union Street, Kingston, Ontario, K7L $3 N 6$, Canada

\begin{abstract}
Several proprietary industrial symbiosis software tools have been developed, however, without long term financial commitments these endeavors fall short of creating generalizable and sustainable tools. The recent development of virtual globes such as Google Earth (GE), an information service that provides imagery and three dimensional data depicting the entire physical earth, provides an opportunity to use a new sustainable method of navigating information to save energy and use materials more efficiently in the real world. To test this open source methodology, a data set was used from the Department of Environmental Protection in Pennsylvania, which has mandated reporting the location of disposal and type of residual waste from sources producing more than one ton per month. This data set was integrated into the GE interface to identify and quantify opportunities for materials and energy efficiency improvements. This investigation found that virtual globes coupled with open source waste information can be used to: 1) reduce embodied transport energy by reducing distances to recycling facilities, 2) choose end of life at recycling facilities rather than landfills, and 3) establish industrial symbiosis and eco-industrial parks on known by-product synergies. For one waste category, a potential $70 \%$ reduction in ton-kilometers was identified by simply observing closer disposal locations than currently utilized; similar reductions are achievable in other categories. It is concluded that the open source sharing of information in virtual globes provide a means to identify economically and environmentally beneficial opportunities for waste management if the data have been made available.
\end{abstract}

\section{INTRODUCTION}

The recent development of virtual globes or earth browsers ${ }^{1}$, such as Google Earth, an information service that provides imagery and three dimensional data depicting the entire physical earth, provides an opportunity to use a new method of navigating information to save energy and use materials more efficiently in the real world [1]. Google Earth has been freely available to the public under a limited license since 2005, providing a means for global navigation through a superimposition of images obtained from satellite imagery and aerial photography [2]. Users are able to create and share layers which integrate information such as points of interest or photographs into the viewing interface. Charities and NGOs have capitalized on the technology to mobilize evolunteers to collate updated imagery following natural disasters such as Hurricane Katrina or the 2005 earthquake in Pakistan, while governments and companies have partnered to assist households in determining the solar energy potential for their rooftops based on imagery [3]. Google Earth can also assist in optimizing material and resource consumption in parallel with the embodied energy of transportation by facilitating the creation of industrial symbiosis (IS) [1]. "Industrial symbiosis engages traditionally separate industries in a collective approach to competitive advantage

*Address correspondence to this author at the Department of Mechanical and Materials Engineering, Queen's University, 60 Union Street, Kingston, Ontario, K7L 3N6, Canada; Tel: 613-533-3369;

E-mail: pearce@me.queensu.ca

${ }^{1}$ There are several virtual globes or earth browsers including NASA World Wind, Marble (KDE), SkylineGlobe, and Bing Maps. involving physical exchange of materials, energy, water, and/or by-products. The keys to industrial symbiosis are collaboration and the synergistic possibilities offered by geographic proximity" [4]. Such a system collectively optimizes material and energy use at efficiencies beyond those achievable by any individual process alone. Often, access to information on available by-products is nonexistent. These by-products are considered waste and typically not traded or listed on any type of exchange.

A recent mandate from the Department of Environmental Protection in Pennsylvania (PA DEP) has made the design of eco industrial parks using industrial symbiosis on the state scale possible. The PA DEP has mandated since 1992 that any company which produces more than 1 ton of residual waste per month must report the type and location of disposal [5]. Residual waste is defined as non hazardous industrial waste. This regulation is enforced through the Residual Waste Management chapter of Pennsylvania's Solid Waste Management Act [5]. The biennial report must quantify the waste, categorize the nature of the waste amongst nine categories and 110 subcategories, list how and where it is handled (on site or otherwise), and describe the waste generator's efforts to reduce the weight or toxicity of the generated waste. In general, companies would otherwise not offer this information voluntarily as it provides competitors a means of evaluating production levels.

The data set made available by the PA DEP and Google Earth functionality provides the unprecedented opportunity to make significant improvements in the efficiency of Pennsylvania industry. A detailed analysis has been undertaken on this data set to quantify the potential life cycle environmental benefits from the reuse of these materials [6]. 
Of the 20 million tons of solid residual waste generated in 2004, approximately $40 \%$ was being used as a substitute for virgin materials savings $13 \mathrm{PJ}$ of fossil-derived primary energy, 0.9 million metric tons of $\mathrm{CO}_{2}$ eq, 4,300 tons of $\mathrm{SO}_{2}$ and 4,200 tons of $\mathrm{NO}_{\mathrm{x}}$ [6]. If all the residual waste were reused, these benefits could increase to $47.2 \mathrm{PJ}, 3.6$ million tons, 19,600 tons and 29,100 tons, respectively [6]. These totals are useful for calculating the total potential economic and impact on the Commonwealth of Pennsylvania if medium and large size industries began to work together to eliminate waste and improve efficiency. This past work [6] has clear potential to drive more efficient materials policy at the state and federal levels. The overview, however, does not provide enough resolution for individual businesses to locate opportunities specifically for themselves and thus does not help implementation on the business-scale.

This paper reports on methods to analyze this Pennsylvania residual waste data to find specific opportunities to improve recycling and reuse of materials, encourage reduced embodied energy of transportation, and drive industrial symbiosis using Google Earth as a tool. It explores these methods of improving environmental and economic performance of the regions businesses and outlines how this method can be generalized to any region. Finally, conclusions and recommendations are made for future work.

\section{METHODS}

The data released by the PA DEP is sorted into nine waste categories and 110 subcategories with the address of each waste generator and disposer. Someone seeking a byproduct synergy or a shortened transportation distance to a reuse or disposal facility currently needs to manually look through this data to find the appropriate waste generator/disposer or a facility within the desired distance. There is a need for a more efficient approach to identifying potential for industrial symbiosis and the reduction of embodied energy of transportation [1].

Keyhole Markup Language (KML) in Google Earth was used to fulfill this need. KML is a programming language which translates information systems containing features such as placemarks, images, polygons, 3D models and textual descriptions into a display for Earth browsers [7]. Each of these features is positioned within the display by its longitude and latitude, and may also include view-specific information such as tilt, heading and altitude to further define the camera view in the browser; this information set is known as its geocoding. The format of this information is standardized amongst different platforms by the Open Geospatial Consortium, an industry consortium, allowing interoperability of the information systems amongst different browsers [8]. Google Earth is one of many programs which utilize KML to create a navigable virtual globe, but it is a good candidate for this project due to three primary reasons. First, it is free to use in its fully functional form for personal use. Second, its use can be augmented by volunteers who create applications using their own data then share the application code [9]. Finally, Google Earth already provides the capability for route planning amongst the world's road system.

The PA DEP data set was integrated into Google Earth. A screenshot of the user interface is shown in Fig. (1). The residual waste is broken down into the PA DEP waste categories with the user being able to display the waste disposal and generation for further subcategories. Waste generation locations are denoted by the brown tags while disposal locations are denoted by green tags. The relative height of the tags indicates the relative waste quantity. The address and waste information for any particular location is summarized in a bubble by holding the mouse over the location as seen in Fig. (2). This particular screenshot displays the waste generation and disposal locations for ferrous baghouse dust, a sub category of metallurgical process residues.

\section{RESULTS}

\subsection{Encourage Recycling}

The KML overlay of PA waste in GE provides a means of encouraging recycling by providing easy access to waste disposal options for individual companies. For example, consider the recycling of slag, which is generated during the separation of molten steel from impurities inside steelmaking. A study concluded that steel making by-products can be utilized along with limestone aggregates without substantially reducing the concrete's compressive strength, and that the water requirements for the steel slag-containing mixes require comparable amounts of water [10]. Another analysis showed that the use of steel slag aggregates along with limestone results in a concrete of superior mechanical performance [11]. As of 2004, 34\% of the 1,074,000 tons of steel slag in Pennsylvania was being recovered for reuse in concrete production [6]. Thus there is a potential to use an additional 700,000 tons of slag in concrete synthesis in the State.

A potential diversion of steel slag from landfill to recycling was identified with the GE tool as is seen in Fig. (2). The 147 tons of annual material flow of steel slag waste currently being sent by Grove US in Shady Grove, PA to the Mountain View landfill in Greencastle, PA could instead be sent to the Clean Earth facility in Hagerstown, MD. The facility in Shady Grove was contacted and queried on their current practice of treating slag as waste and paying to have it sen to a landfill. They replied that they were involved in efforts to reduce their waste output, but would be interested in pursuing a relationship with the Clean Earth Facility ${ }^{2}$. Similar short information exchanges could be coordinated either by government environmental/waste disposal personnel to optimize the use of materials in a jurisdiction, service learning projects run through universities [12] or it could be coordinated by for-profit companies such as Clean Earth Facilities to gather more customers.

As a second example, consider ferrous grindings and shavings, which are generated from the production, forming and machining of steel. The material flow of ferrous grindings and shavings in the Pennsylvania state area are seen in Fig. (3). Numerous technologies exist to recover iron from by-products to the steelmaking which have shown to be attractive due to little capital cost to steel plants and significant decreases in landfill costs [13]. The two large-

\footnotetext{
${ }^{2}$ Kesner M. Personal Communication. Grove US LLC: Shady Grove, PA,
} 2009 


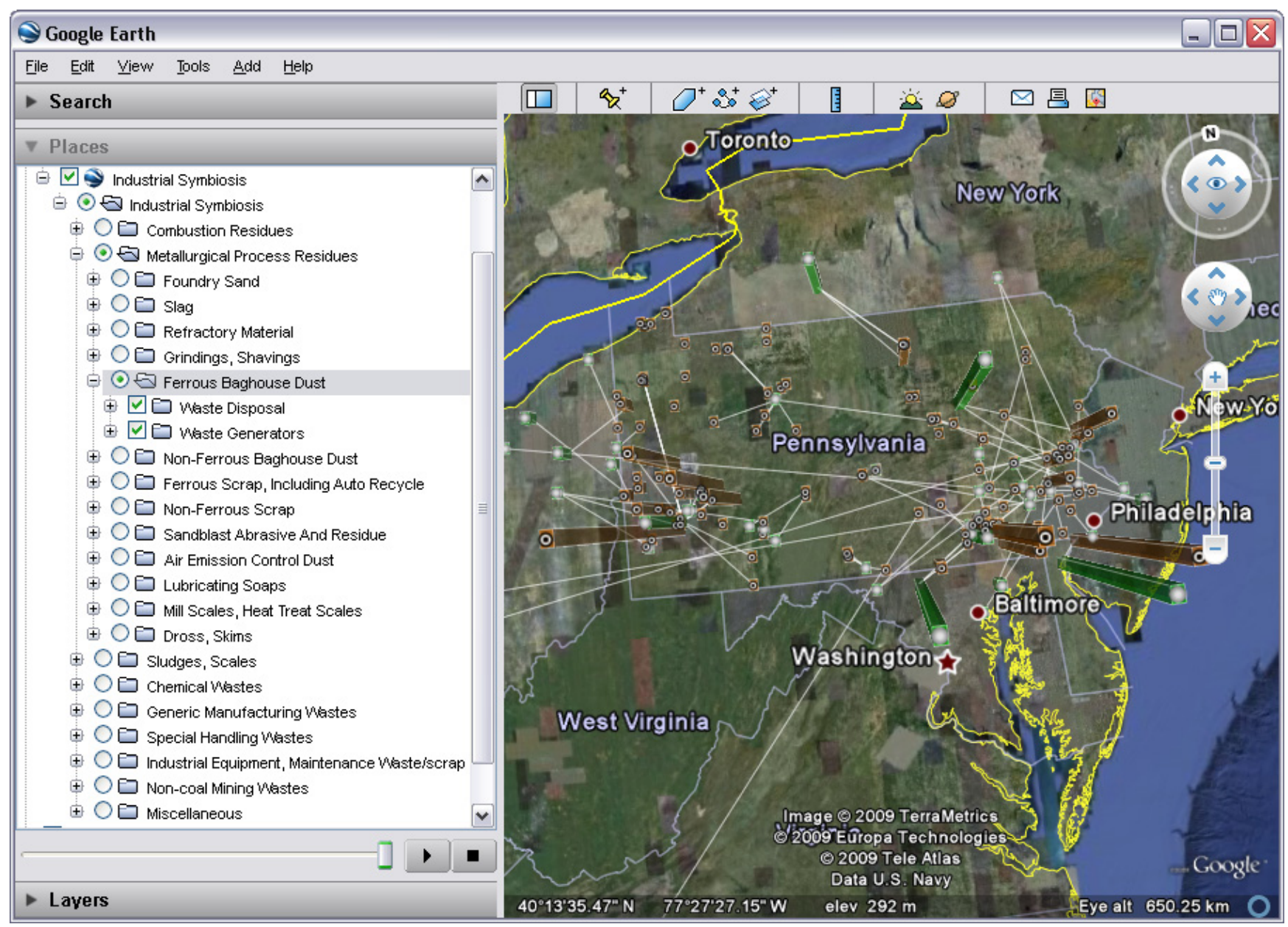

Fig. (1). The Google Earth user interface with industrial symbiosis coding. The residual waste is broken down into 13 categories with the user being able to display the waste disposal and generation for further subcategories. Waste generation locations are denoted by the brown tags while disposal locations are denoted by green tags. The white lines connect sources and destinations. The relative height of the tags indicates the relative waste quantity.

volume waste generators seen in the figure near Philadelphia are located near disposal locations which handle all their waste through reuse processes. Many of the numerous smaller-volume generators around the state are sending their materials to landfills. Companies often classify such byproducts as waste and discard it to landfills at significant cost, but the reality is that they offer significant potential for cost savings or profit if reintroduced into the industrial area via well planned programs [13]. Koros reasons that landfilling of these by-products occurs where local economics make the alternative attractive. With use of the GE tool, generators of ferrous grindings and shavings can identify potential savings by searching for nearby steel makers to reuse what would otherwise be treated as waste. As of $2004,42 \%$ of the 117,000 of ferrous scrap and dust in Pennsylvania was being recovered for substitution of virgin steel [6]. Again and additional 67,000 tons of ferrous scrap can be reused.

\subsection{Encourage Waste to Resource Conversion}

Although not all materials can be recycled there are still many options before landfilling is necessary. Consider the case of flue gas desulphurization (FGD) residue, which is nearly always treated as a waste product. FGD is a technology used to remove sulfur dioxide from exhaust flue gases in polluting coal or oil-fired thermal power plants. Wet slurries are brought into contact with the polluted gas stream in order to remove the pollutants. A sludge residue results from this process; most power plants dispose of it in nearby landfills despite there being economic reuses for most grades of the residue [14]. The material flow of FGD residue in the Pennsylvania state area is seen in Fig. (4). FGD residue high in calcium sulphate can substitute for gypsum, while manufacturers of low-strength cement can utilize residue high in calcium sulphite in low-strength cement mixtures [15]. Specific uses for FGD residue high in calcium sulphate include use in wall-board manufacturing for high-quality sludge while there are ongoing developments in the use of organic and inorganic impurity-containing sludge in the manufacture of architectural products such as bathroom tiles and counter tops [14]. As of 2004, 44\% of the 3,242,000 tons of FGD residue in Pennsylvania was being recovered for substitution of gypsum [6]. With use of the GE tool, generators of FGD residue can identify potential savings by searching for by-product synergies with wall board and tile manufacturers to find further use for what would otherwise be treated as waste. 


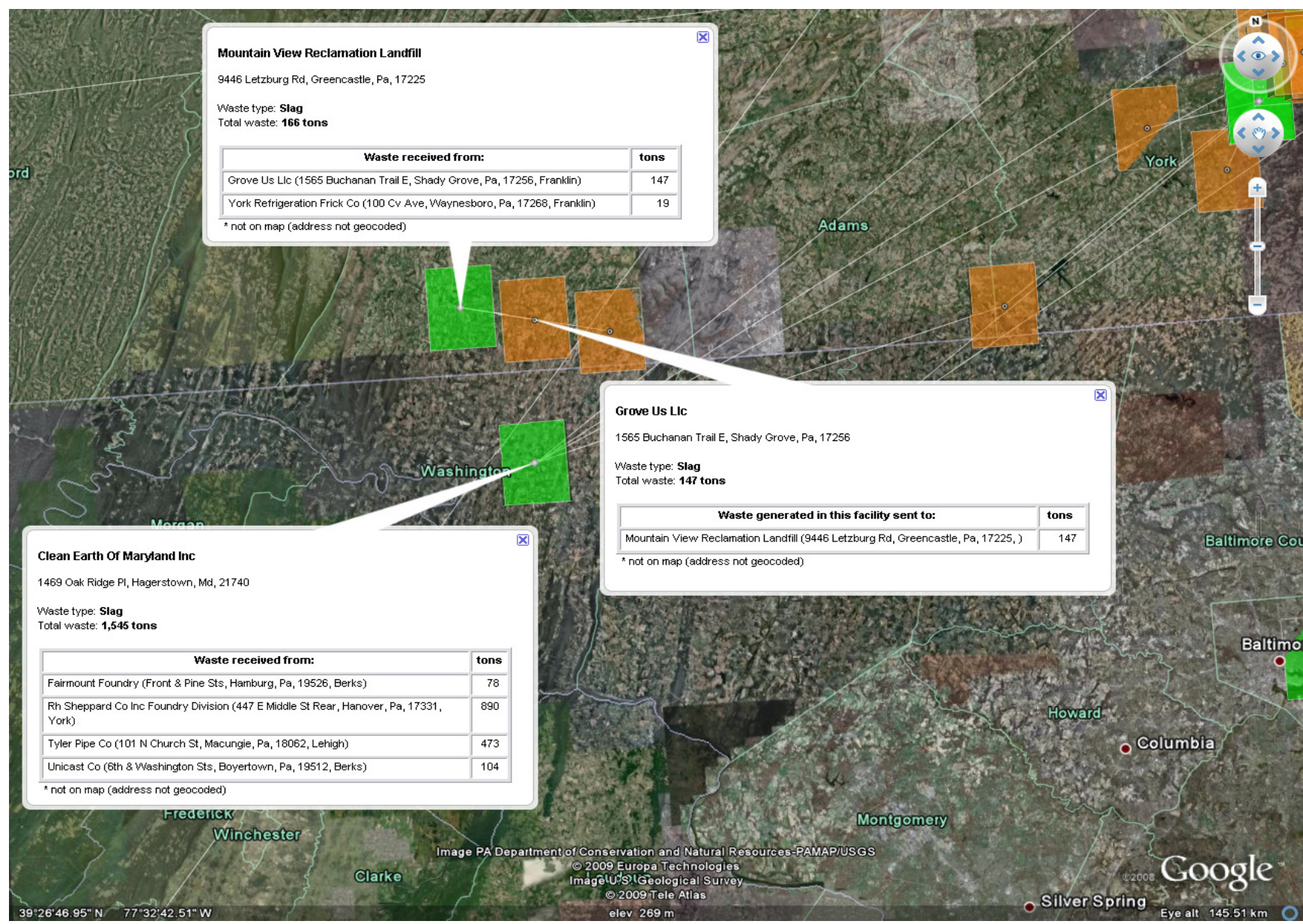

Fig. (2). The material flow of steel slag waste currently being sent by Grove US to the Mountain View landfill in Greencastle, PA could instead be sent to the Clean Earth facility in Hagerstown, MD.

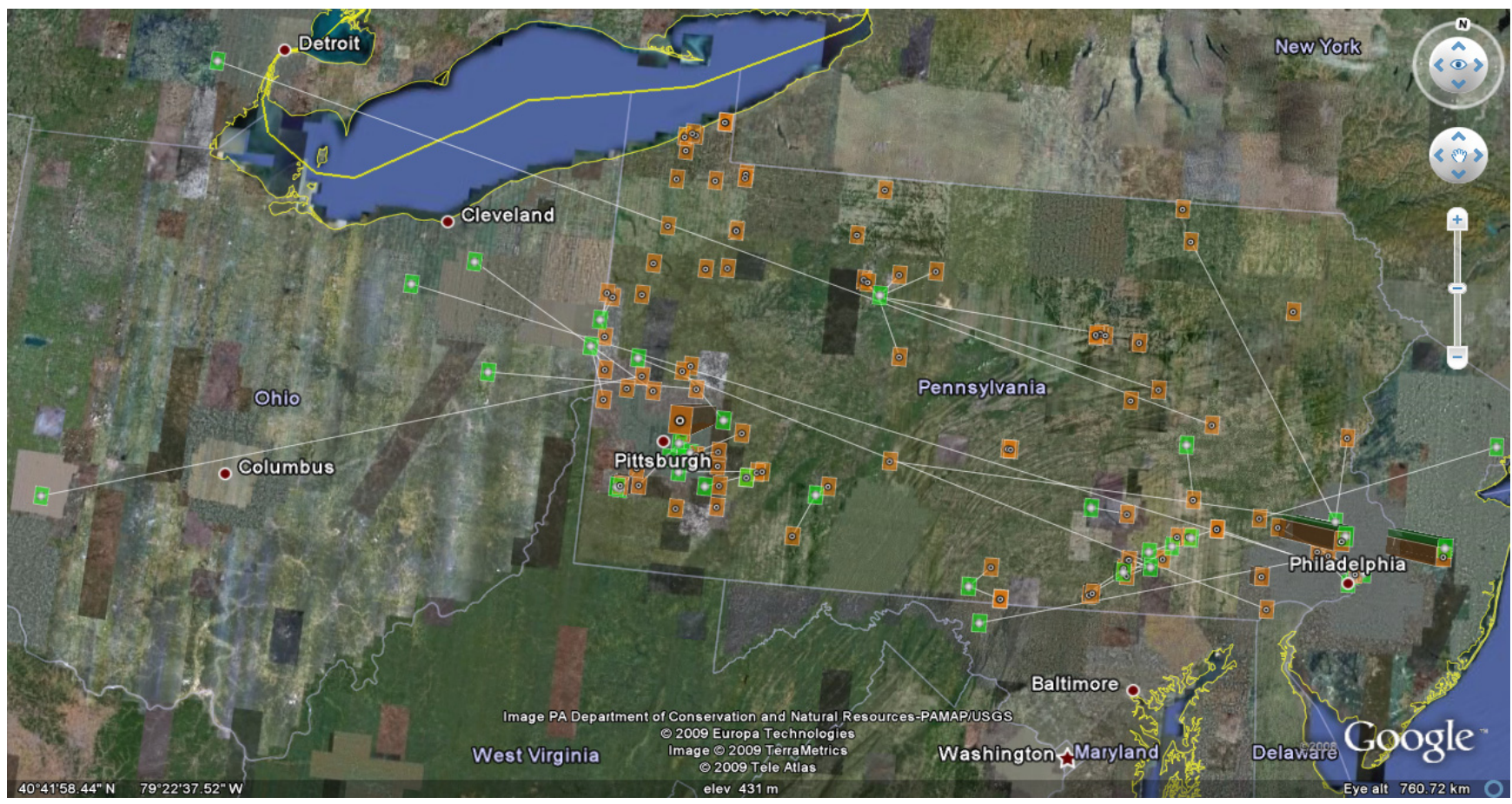

Fig. (3). The material flow of ferrous grindings and shavings in the Pennsylvania state region. The two large-volume waste generators (brown) near Philadelphia are located near disposal locations (green) which handle all their waste through reuse processes. Many of the numerous smaller-volume generators around the state are sending their materials to landfills. 


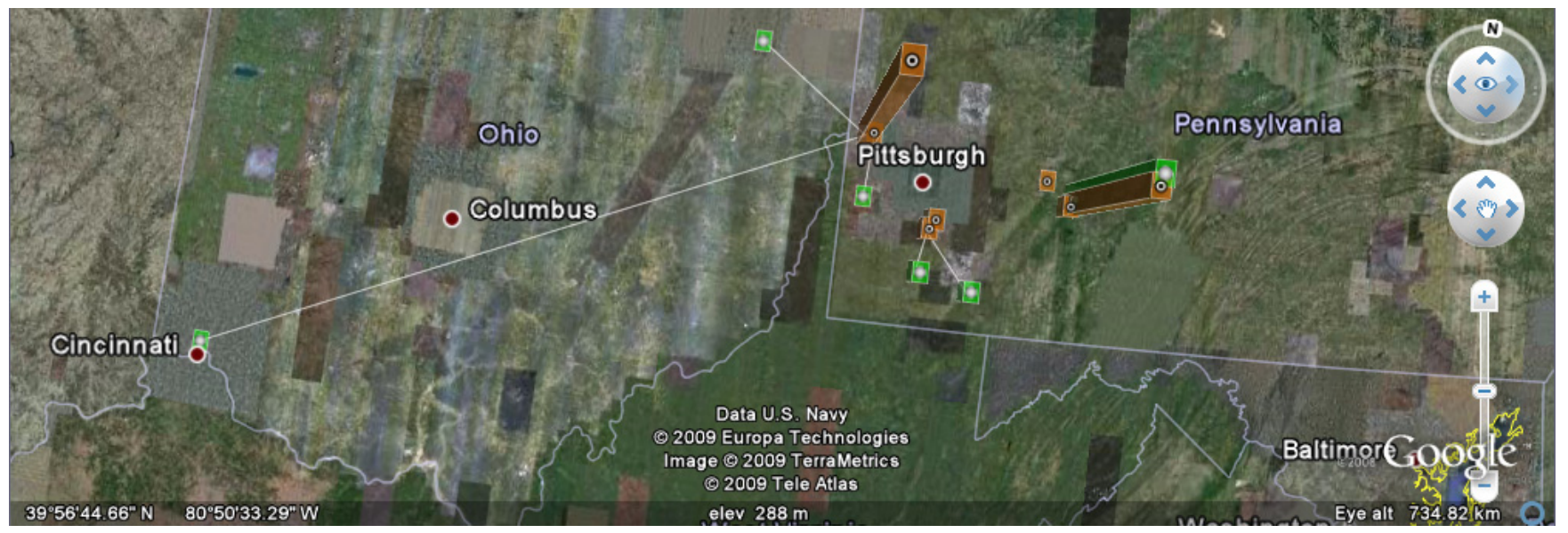

Fig. (4). The material flow of FGD residue in the Pennsylvania state region. FGD residue can substitute for gypsum in manufacturing processes such as drywall and tiles. Such a waste-to-resource by-product synergy could be encouraged to avoid the landfill disposal of this FGD residue.

\subsection{Reducing Embodied Energy of Transportation}

Regardless of how a material is disposed (recycled/reused or landfilled), the distance and means of transportation between the generation and the disposal determines the embodied energy of transportation and thus a component of the overall environmental impact of the product. The GE tool can be used to optimize this transport to reduce the amount of embodied energy of transportation [1]. As an example of the importance of this area of inquiry, consider the case of non-hazardous waste oil generated from many processes including motor oils and metal working lubricants. When viewing the PA DEP data set for nonhazardous waste oil on GE, it is evident that there currently is substantial transportation of this residual waste to locations across the United States. This is seen in Fig. (5) with the in-state waste generation and disposal locations seen in their own insets. This oil is contaminated by physical (e.g., high water content, metal shavings, or dirt) or chemical (e.g., lead or solvents) impurities as a result of use. In the United States, it is estimated that as much as 90 percent of all collected used oil is burned for energy recovery with ten percent or less being re-refined into lubricating oil [16]. As of 2004 , only $16 \%$ of the 380,000 tons of waste oil in Pennsylvania was being recovered for reuse [6]. In addition to identifying the potential to save 319,200 tons of waste oil, the GE tool was used to visualize the opportunity to reduce oil used to transport this waste throughout the country. As an example of the extremes undertaken to transport materials, one metal products manufacturer in Bellefonte, PA currently sends their 46 tons of annual oil waste the $2,225 \mathrm{~km}$ to a recycler in Plano, TX when there is a waste oil recycler located $220 \mathrm{~km}$ away in Lancaster, PA. The metal products manufacturer sells their waste oil to the Texas facility where it is reprocessed then sold for further use as automotive lubricant. The facility in Lancaster, however, processes the oil and sells it to cement kilns for combustion to capture the residual energy content. The metal products manufacturer would consider the Lancaster facility as a destination for its waste if it was cost-competitive to their current processes ${ }^{3}$.

${ }^{3}$ B. Persafage, Personal Communication. Cerro Metal Products: Bellefonte, PA, 2009.
Should the waste oil generator opt for the closer facility, the annual environmental savings of transporting the 46 tons of waste (15.8 ton kilometers/liter) via truck a distance 2005 $\mathrm{km}$ shorter amounts to 5,840 liters of fuel or $14,600 \mathrm{~kg}$ of $\mathrm{CO}_{2}$ [17]. As about $1,100 \mathrm{~L}$ of waste oil weighs a ton, over $11 \%$ of the oil being recycled is burnt transporting it to the recycler in Texas [18].

Substantial reductions in the embodied energy of transportation are achievable in all waste categories. The existing waste flows of spent fluids from the plating of metals are seen in Fig. (6). It is seen that all the waste generators are shipping the spent plating fluids to disposal locations spread around Pennsylvania and beyond. The distance of transport from waste generation to current disposal location was compared to the distance of the closest disposal location. It is found that there is a potential for reduced transportation from 14,638 ton-kilometers to 4,590 ton-kilometers, a $70 \%$ reduction. Similar reductions are achievable in many other waste categories.

\subsection{Siting of Eco-Industrial Parks}

The strategic co-location of facilities with complementary input/output needs can provide an economic advantage to businesses and help drive down the costs of renewable energy sources such as photovoltaic cells $[4,19]$. The use of Google Earth to identify potential matches within existing industries could be further used by economic development groups to attract new businesses to the area based on available waste streams that could become inputs for the new businesses. The material flow of steel slag in the Pennsylvania state area is seen in Fig. (7). As discussed above, steel slag can be readily substituted for concrete aggregates. This is occurring in the large-quantity co-located facilities seen in Pittsburgh, but numerous opportunities exist for the establishment of regional eco-industrial parks of concrete production around smaller-volume steel slag producers. Such potential is easily identified with the GE tool by observing the existing material flow from clusters of steel manufacturers situated to the North and West of Philadelphia directly to regional landfills. 


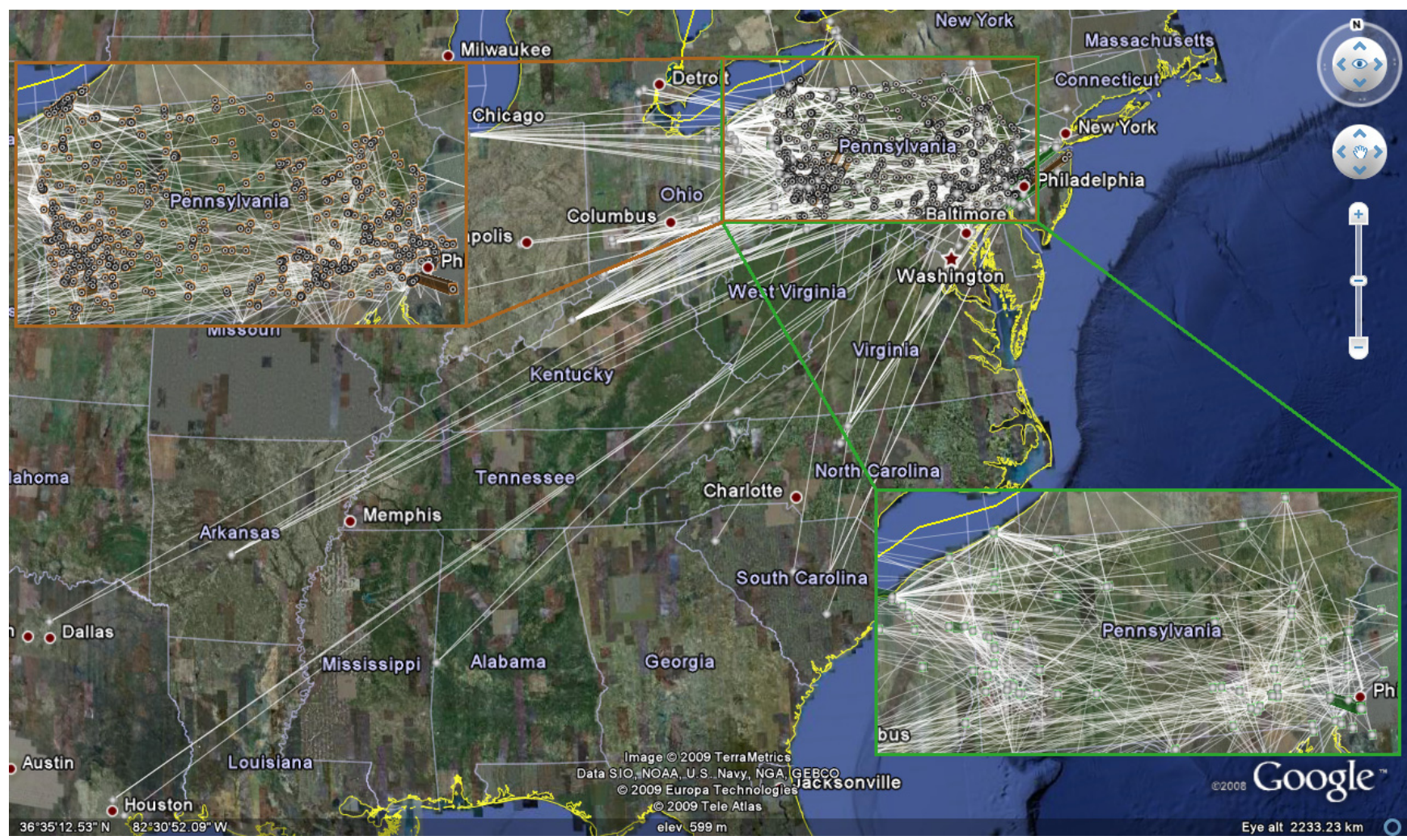

Fig. (5). The material flow of waste oil generation and disposal sites across the United States with an inset of Pennsylvania generators in brown and disposers in green. Waste oil from one generator in Pennsylvania could send it to an in-state disposal location $220 \mathrm{~km}$ away rather than send it 2,225 $\mathrm{km}$ to a location in Texas.

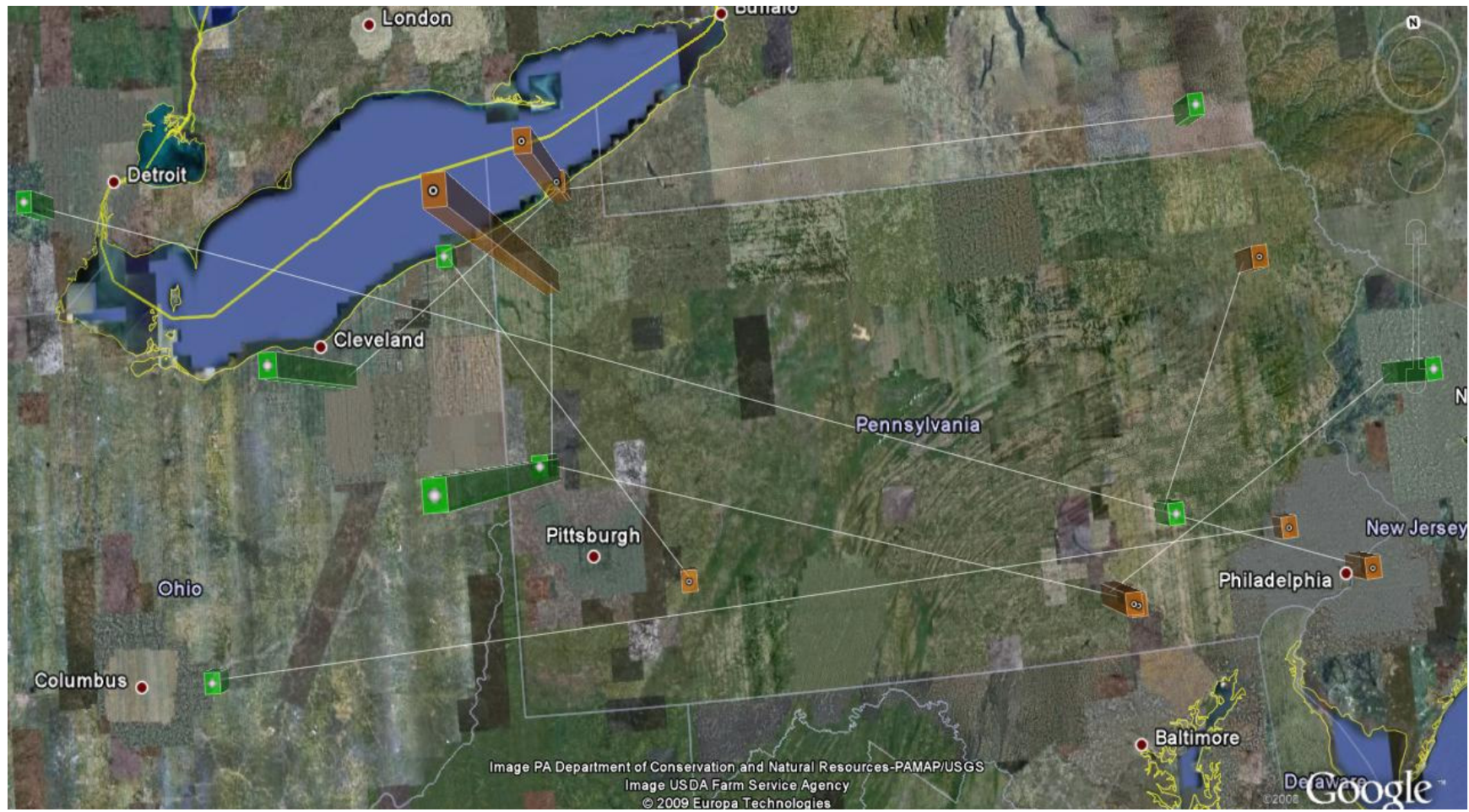

Fig. (6). The existing waste flows of spent fluids from the plating of metals. All the waste generators are shipping the spent plating fluids to disposal locations spread around Pennsylvania and beyond. The distance of transport from waste generation to current disposal location was compared to the distance of the closest disposal location. It was found that there is a potential for reduced transportation from 14,638 tonkilometers to 4,590 ton-kilometers, a $70 \%$ reduction. 


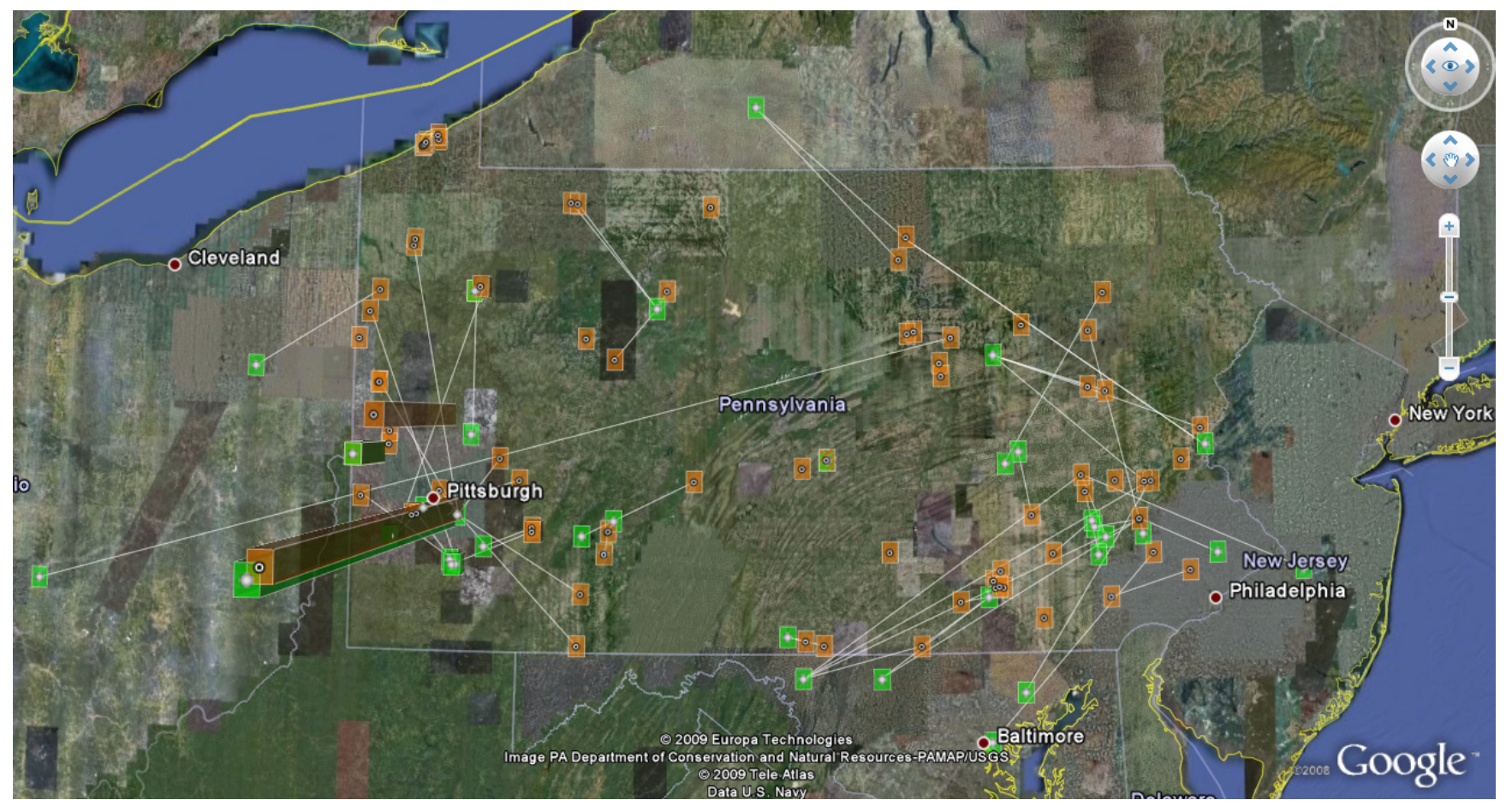

Fig. (7). The material flow of steel slag in the Pennsylvania state region. Steel slag can be readily substituted for concrete aggregates as is occurring in the large-quantity co-located facilities seen in Pittsburgh. Numerous opportunities exist for the establishment of regional ecoindustrial parks of concrete production around smaller-volume steel slag producers.

\section{DISCUSSION AND FUTURE WORK}

In past investigations of the potential for IS and the reduction of embodied energy of transportation in regions around the world, different methods have been used to aggregate and view the waste data. Funded by grants, certain proprietary industrial symbiosis identification tools have been developed with varying levels of success. They are all alike in their manner of data collection from industries: individual companies were approached and invited to participate in the program, then the data set was input by those developing the tool. Without any long term commitment on the part of the industries or the funding bodies, these endeavors fall short of creating implementable and sustainable tools.

One IS tool developed in North Carolina is an example of an initiative which was developed in conjunction with local industries but is not scalable. The project investigated potential by-product partnerships within a six-county metropolitan area in North Carolina encompassing a population of approximately 1 million [20]. A list of large industries and institutions that were deemed to be able to benefit from such partnerships were approached for participation in the project, being offered confidentiality and the potential for economic savings. Surveys were performed at participating companies to identify lists of potentially reusable items as well as lists of the inputs used for processes which might be sourced from the byproducts of other facilities. This database was coupled with a commercially available GIS system, ArcView GIS, to identify potential partners within a particular radius of any of the facilities. The GIS maps displayed the amount and type of inputs used and by-products produced from each facility. Partnerships identified at this stage were further pursued by researching literature and facilitating discussions and negotiations. The study concludes with a discussion of the importance of an agent to promote the vision of such webs of material exchanges. Such webs require the gathering of information about available by-products or raw materials from individual businesses. With no more funding, the project could not possibly expand to state-wide or greater scale due to the substantial effort required for one person or group to input each industry's data into the unique program. The GE tool overcomes the funding and scalability obstacle by creating the potential for each business to share their waste data through the available program

Another IS tool is under ongoing development for use in the Geneva region in Switzerland. This tool also provides means for identifying potential reductions in the embodied energy of transportation. A Masters study at the University of Lausanne has collaborated with nineteen participating companies in the Geneva region to provide input and output data of great detail including energy, pressure, concentration, temperature, quantity and market value [21]. The author compiled this information along with geographic information in a specific format and devised code which analyses potential partnerships. This code was integrated into a user interface with two types of searches, using a commercially available system, Manifold GIS, as the Earth browser. In one type, a user selects their own company or all companies from one drop down menu and can choose a single company or all companies from a second drop down menu which has already filtered out companies which do not contain synergies from the first-selected company. If multiple potential synergies exist, the user can further filter to one synergy type. A map is produced showing the potential synergies and the direction and Euclidean distance of this 
material flow. The second interface type allows a single company to search for synergies (input or output) within a certain radius- this can allow the company to identify potential partners which are located within a shorter distance than their current partner. The project implementor encountered greater difficulty than expected in accurately locating each facility on the software, and found the volume of work for the data collection of the nineteen participating companies to be very time consuming. Similar to the tool developed in North Carolina, this one struggles with the challenge of scaling the data collection to a larger number of businesses. It is imperative that the data input for such a system be simplified to the point that the waste generators themselves can easily input the data. The GE tool used in this study, is also superior to that used in Geneva to identify potential reductions in the embodied energy of transportation because GE provides travel distances based on driving routes and not merely Euclidean distances.

Google Earth stands to fulfill the shortcomings encountered in previous experiments on IS software. "Google Earth could provide a framework for mapping industrial processes, and their associated material and energy flows, to help discover opportunities for by-product synergies" [1]. While some of the previously developed tools have been shared publicly, the much needed industry data sets were not shared successfully between users. As has been exhibited above, the extensive data collected by the PA DEP which has been applied to Google Earth provides a navigable and thorough map-based database of residual waste.

Unless this data collection is mandated by law as in Pennsylvania, companies will continue to operate independently in managing their residual waste. In keeping with its obligations as a signatory of the Kyoto Protocol, Canada produces an annual national greenhouse gas emissions inventory for six main green house gases [22]. This inventory produces estimates of the emissions for different industrial processes based on mandatory facility reporting; there is no legal obligation or central inventory for companies to share their non-GHG wastes. If law enforced all companies to locate their facilities on Google Earth (or some similar open access free platform) and quantify and describe the nature of their waste, a database of opportunities for industrial symbiosis and reduction of embodied energy of transportation would be formed. The greater the detail of the composition of the waste provided by the companies, the more likely that appropriate synergies and transportation reduction opportunities could be identified. Entrepreneurs or company representatives could take advantage of this database to further investigate identified opportunities for feasibility, and complement the data with links to information about by-product synergies. If residual waste data were entered in a standard format, algorithms could be implemented to further enable and automate such investigations. The promotion of such a residual waste reporting law can be made on the grounds of the environmental and economic benefits inferred by the examples in this paper.

\section{CONCLUSIONS}

This paper analyzed parts of the available PA industrial waste data using Google Earth's framework for mapping industrial processes, and their associated material and energy flows in order to discover opportunities for by-product synergies. This data set was used to determine and quantify examples of the following: 1) opportunities to choose end of life at recycling or reuse rather than landfill, 2) opportunities to reduce transport distance to recycling facilities, and 3) opportunities for industrial symbiosis and eco-industrial parks on known by-product synergies. This preliminary work showed that an incredible opportunity exists to improve industrial efficiency by first mandating industrial reporting of wastes by appropriate governmental organizations and secondly making this information available in an open format for applications such as with Google Earth.

\section{ACKNOWLEDGEMENTS}

The authors would like to acknowledge helpful discussion with Gabriel Grant, Carlos Camara Ortiz, and David Tryse. In particular we would like to point out the invaluable coding in Google Earth by David Tryse, which made this work possible.
ABBREVIATIONS

DEP $=$ Department of Environmental Protection
FGD $=$ Flue Gas Desulphurization
GE $=$ Google Earth
GHG $=$ Greenhouse Gas
GIS $=$ Geographic Information Systems
IS $=$ Industrial Symbiosis
KML $=$ Keyhole Markup Language
PA $=$ Pennsylvania

\section{REFERENCES}

[1] Pearce JM, Johnson SJ, Grant GB. 3D-mapping optimization of embodied energy of transportation resources. Conserv Recycl 2007; 51: 435-53.

[2] Google. Google Earth Product Information and Download. [on the Internet]. 2009; [cited 2009 March 30]. Available from: http://earth.google.com

[3] Nourbakhsh I, Sargetn R, Wright A, et al. Mapping disaster zones. Nature 2006; 439: 787-8.

[4] Chertow MR. Industrial symbiosis: literature and taxonomy. Ann Rev Energy Env 2000; 25: 313-37.

[5] Commonwealth of Pennsylvania. Residual Waste Management. Solid Waste Manage Act 1992; Chapter 287.

[6] Eckelman MJ, Chertow MR. Quantifying life cycle environmental benefits from the reuse of industrial materials in Pennsylvania. Environ Sci Technol 2009; 43(7): 2550-6.

[7] Blom M. Investigating the Spatial Variation of Renewable Energy Potential in the UK, Masters of Science Thesis. London: City University, 2008.

[8] Open Geospatial Consortium, [on the Internet]. 2009; [cited 2009 March 24]. Available from: http://www.opengeospatial.org

[9] Goodchild MF. Citizens as sensors: the world of volunteered geography. GeoJournal 2007; 69: 211-21.

[10] Tüfekçi M, Demirba A, Genç H. Evaluation of steel furnace slags as cement additives. Cem Concr Res 1997; 27: 1713-7.

[11] Maslehuddin M. Comparison of properties of steel slag and crushed limestone aggregate concretes. Constr Build Mater 2003; 17: 10512.

[12] Pearce J, Russill C. Interdisciplinary environmental education: communicating and applying energy efficiency for sustainability. Appl Environ Educ Commun 2005; 4(1): 65-72. 
[13] Koros PJ. Dusts, scale, slags, sludges... not wastes, but sources of profits. Metall Mater Trans B 2003; 34(6): 769-79.

[14] Malhotra VM, Chugh YP. Tile, Countertops, and structural materials from sulfate-rich FGD scrubber sludge. Ashlines 2005; 6: $1-8$.

[15] Ritchey KD, Elrashidi MA, Clark RB, et al. Potential for utilizing coal combustion residues in co-utilization products. In Brown S, Scott Angle JS, Jacobs L. Beneficial Co-Utilization of Agricultural, Municipal and Industrial By-Products. New York: Kluwer Academic Publishers, Springer: 139-47, 1998.

[16] Environmental Protection Agency. Materials characterization paper in support of the advanced notice of proposed rulemaking identification of nonhazardous materials that are solid waste - used oil. Environmental Protection Agency, December 16, 2008.
[17] Congressional Budget Office. Energy use in freight transportation. [on the Internet]. 1982; [cited 2009 March 30]. Available from: http://cbo.gov/doc.cfm?index $=5330 \&$ type $=0$

[18] White FM. Fluid Mechanics. $5^{\text {th }}$ ed. New York: McGraw Hill 2003.

[19] Pearce JM. Industrial Symbiosis for Very Large Scale Photovoltaic Manufacturing. Renew Energ 2008; 33: 1101-8.

[20] Kincaid J, Overcash M. Industrial ecosystem development at the metropolitan level. J Ind Ecol 2001; 5(1):117-26,

[21] Plancherel A. Valorisation des SIG pour la detection de synergies éco-industrielles. Master of Science thesis presented for Swiss Institute of Technology/University of Lausanne, 2006.

[22] Environment Canada. Canada's GHG Inventory. [on the Internet]. 2009; [cited 2009 March 30]. Available from: http://www.ec.gc.ca/ pdb/ghg/inventory_e.cfm

(C) Doyle and Pearce; Licensee Bentham Open

This is an open access article licensed under the terms of the Creative Commons Attribution Non-Commercial License (http://creativecommons.org/licenses/bync/3.0/) which permits unrestricted, non-commercial use, distribution and reproduction in any medium, provided the work is properly cited. 